\section{O delírio cibernético de Norbert Wiener}

\section{RESUMO}

Esse texto trata da condição do mundo cada vez mais mediado por uma espécie de ciber-hifenização delirante da realidade que parece ter começado a partir do pensamento de Norbert Wiener.

\section{ABSTRACT}

This text argues that the world condition is increasingly more and more mediated by a certain delirious cyber-hyphenization of reality which seems to have began from Norbert Wiener's thoughts onwards.

\section{PALAVRAS-CHAVE/KEY-WORDS}

- Cibernética (Cybernetics)

- Teoria da comunicação (Communication theory)

- Sociologia da comunicação (Sociology of communication)

\section{Stephen Pfohl ${ }^{\star}$}

Prof. Depto. Sociologia do Boston College, Ma. - USA

\begin{abstract}
"Meu delírio tomou a forma de uma particular mistura de depressão e preocupação... de uma ansiedade sobre o status lógico do meu... trabalho. Para mim era impossível distinguir entre minha dor e dificuldade em respirar, um barulho da cortina e certos pontos até agora não resolvidos do problema em potencial no qual eu estava trabalhando. Não posso dizer que a dor se revelou como uma tensão matemática, ou o que a tensão matemática tenha sido simbolizou como dor: os dois estavam muito próximos para fazer tal separação significativa. No entanto, quando refleti sobre esse assunto mais tarde, eu me dei conta da possibilidade de que qualquer experiência pode agir como um símbolo temporário para uma situação matemática que ainda não tinha sido organizada e esclarecida. Também pude ver mais claro do que antes que um dos principais motivos que me levaram à matemática foi o desconforto ou mesmo a dor provocada por um contencioso matemático não resolvido. Eu até mesmo fiquei mais e mais consciente da necessidade de reduzir tal contencioso a termos econhecíveis e semipermanentes antes de poder largá-lo e ir adiante em outra coisa." (Norbert Wiener ${ }^{1}$ )
\end{abstract}

TUDO AO MEU REDOR, dentro de mim, fluindo através de mim, entre mim e os outros - é fácil discernir os signos do marketing de massas flexível do delírio cibernético: esse é um delírio associado, ao mesmo tempo, com os ciberprodutos e com a experiência cibernética. Ciberisso e ciberaquilo: é difícil fazer o ritual da fila de checagem das 
suas coisas hoje em dia, sem conectores de mercadorias magneto-cibernéticas envolvendo seus sensores sedutores colados no seu rosto, em giros que se realimentam por seu intermédio. Trata-se de uma atenção imperativa; de convite a uma tentativa.

Não que os efeitos sejam homogêneos, muito menos as possibilidades. Da vigilância, das compras e do sexo cibernético à ciberfilosofia e mesmo aos sonhos utópicos da rebelião dos cyborgs - seja por diversão, ou por desespero, por desejo ardente ou por querer conexões mais apaixonadas e politicamente efetivas -, o mundo ao redor e dentro de mim aparece cada vez mais mediado por uma espécie de ciber-hifenização delirante da realidade. Esta é uma curta história (story) sociológica da história (history) desse mundo hifenizado, que gira em torno do delírio de Norbert Wiener, o chamado pai das perspectivas cibernéticas na realidade social e física. Hoje em dia, o delírio de Wiener se tornou o nosso.

Minha sugestão é esta: para o pior ou o melhor estamos virtualmente todos lutando para sobreviver e se comunicar - ainda que diferentemente e de modos diferentes - dentro das exigências hegemônicas da cultura cibernética. Rápidas correntes da British Telecom; ligeiros solavancos de lucro: tchau, tchau $\mathrm{MCl}$. 182.000 empregos se movendo; setenta países: valor de mercado, US\$ 64 bilhões - uma implosão de lágrimas. "Oi, mãe! Feliz dia dos namorados!"

Um fragmento giratório de memória agarra o meu olho ou o meu eu (eye/l), enquanto a informação inflama as ligações sensoriais entre nós; me ligando; me desligando; virando a história de dentro pra fora. O barulho de uma cortina. A suavidade digital de uma tela separando meu corpo das imagens informatizadas. $O$ bruxuleio das fantasias e medos mediados eletronicamente entre nós: corpos ligados, corpos rígidos; corações microssuaves (microsoft), energeticamente excitados, e elegantemente abandonados. Eu amo a propaganda tatuando o seu sexo. Você ama o meu Calvin Klein Infinity. Ou a isso eu sou levado a imaginar? Sonhar acordado; no cartão de crédito: isso é o capital cibernético; isso é o poder ultramoderno uma grade branca digitalizada de prazeres e dores ansiosas e informacionais. "Como os presidentes das grandes corporações e os consultores especialistas da classe virtual triunfantemente proclamam: Adaptese ou você está fuzilado" ${ }^{2}$... sente-se o odor de carne queimada.

A Cibernética denota, tipicamente, o estudo interdisciplinar e o emprego estratégico dos processos de controle comunicativo em "sistemas complexos" constituídos por humanos, outros animais, máquinas e o resto da natureza viva. No que vem a seguir, eu gostaria de sugerir um uso ainda mais amplo desse termo. Compreender a cibernética não só como um campo de pesquisa e aplicação tecnocientífica, mas como um termo conotando as formas ultramodernas de controle social que possuem o maior alcance possível. Nesse sentido, eu estarei usando a expressão cibernética social para configurar provisoriamente 0 feedback positivo e negativo que resulta das camadas fluidas, de alta velocidade e densa estratificação, das redes de comunicação que, nesse exato momento, afetam os modos em que você está recebendo minhas palavras.

Esta é uma história de como os giros do feedback cibernético estão informando a organização ritual energética de poder entre nós e os outros. Dentro das fronteiras em rápido processo de flexibilização do capital global, o mais dominante, mas certamente não todos desses giros de feedback, tem uma carga masculina, heterossexista e racialmente marcada: essa é a história do presente.

Descentralizados, já que os giros de feedback comunicativo podem aparecer de dentro de várias cenas localizadas do capital, as práticas de controle cibernético 
guiam o marketing hegemônico de ambas as sobrevivências, a material e a expressiva, dentro dos confins corporais de um sistema socioeconômico cruel, complexo e contraditório. Cada vez mais esse sistema - capital no seu modo ultramoderno ou cibernético - está incorporando o mundo inteiro como o seu parque de diversões lucrativo e parasitário. Eu faço essa sugestão não para promover os giros de feedback comunicativo existentes, algo que faz o mercado televisionário de medos (e fascinações) paranóicos um grande negócio. Pelo contrário, é para se juntar de um modo menor com outros a encorajar uma concertação heterogênea dos esforços coletivos, energéticos e sensíveis ao poder a refletirem e, assim, conversar melhor (teoricamente) - mas também esmagar, subverter, entortar e, de qualquer jeito possível, contribuir para a transformação ritual da - sobre a - "ordem das coisas" violenta e enjoativamente hierárquica, na qual eu me acho escrevendo para você. Trata-se de avançar no sentido de transformações parciais e provisórias; transformações na direção de formas organizacionais rituais que são apenas mais afirmadoras da vida e mais amorosas.

A palavra cibernética deriva do grego kybernetes e refere-se aos mecanismos que permitem dirigir, governar e controlar. O termo foi usado pela primeira vez em relação à engenharia humana - talvez delirantemente - pelo matemático do MIT Norbert Wiener, durante e imediatamente após a II Guerra Mundial. Afinal de contas, era tempo de guerra. Primeiro quente, depois fria.

como Paul Virilio astutamente observa, uma cultura de guerra também é uma cultura do delírio - uma cultura em que as ferramentas de percepção ordinárias são sugestiva, ritual, espetacular, tecnológica e quase alucinatoriamente remanejadas. ${ }^{3}$ Wiener tinha algo de criança prodígio. Foi Ph.D. de Harvard, em matemática, aos 19 anos. Ele foi também um pioneiro na aplicação da matemática não-linear baseada estatisticamente aos problemas de causalidade circular e de feedback autoajustável.

Como parte do esforço de guerra, Wiener colaborou com Julian Bigelow e outros matemáticos e cientistas, reunidos sob o patrocínio do Laboratório de Radiação do MIT. Dirigido por Warren Weaver, da Fundação Rockfeller, esse laboratório era um projeto, seção D2, de alta prioridade, comandado pelo Comitê de Pesquisa para Segurança Nacional. Wiener e Bigelow fizeram usos inovadores e de uma complexidade sem precedentes dos teoremas ergódigos e das equações integrais, o que foi descrito como uma revolução na engenharia de comunicações (computacional). Durante os anos finais da guerra, essa revolução detonou avanços significativos no design, produção e emprego estratégico de armas antiaéreas e de equipamento de bombardeio de precisão. Depois da guerra ela iria mudar todo um modo de vida.

Os trabalhos matemáticos inovadores feitos pelos autores estavam inseridos de maneira complexa e militarmente mediada nos circuitos de feedback comunicativo que estavam sendo dados, ao mesmo tempo, por outros saltos exponenciais que ocorriam na computação e nas comunicações. Muitos desses avanços foram possíveis pelo refinado desenvolvimento do tubo a vácuo. Descrevendo esses eventos, Wiener deixa ver, porém, que foi o tempo de guerra que apressou a produção da imaginação cibernética.

Apesar do tubo a vácuo ter tido o seu início na indústria das comunicações, os limites e extensão dessa indústria não foram totalmente compreendidos por um longo período. Havia usos esporádicos do tubo a vácuo e da sua invenção irmã, a célula fotoelétrica, para verificar a produção industrial, como, por exemplo, na verificação da espessura de uma trama vinda de uma máquina de papel ou na inspeção da cor de uma lata de abacaxis. 
Porém esses usos não formaram uma nova técnica fundamentada e, também, não chegaram a ser associados, nas idéias da engenharia, com um outro uso do tubo a vácuo: as comunicações.

Tudo isso mudou com a guerra. Uma das poucas coisas obtidas do grande conflito foi o rápido desenvolvimento dessa invenção, sob o estímulo da necessidade e do ilimitado emprego de dinheiro... No começo da guerra, a nossa grande necessidade era prevenir a Inglaterra de um ataque aéreo em massa. Conseqüentemente, o código antiaéreo foi um dos primeiros objetos de esforço científico, especialmente quando combinado com o aparelho de radar detector de aviões ou as ondas hertzianas de alta e ultrafreqüência. A técnica do radar usou as mesmas modalidades já existentes no rádio, assim como outras novas, de modo que se tornou natural considerar o radar como uma ramificação da teoria das comunicações.

"Além de localizar os aviões por meio de radar, também era necessário derrubá-los. Isso envolve o problema do controle de fogo. A velocidade do avião fez necessária a computação dos elementos da trajetória do míssil antiaéreo por máquinas para dar à máquina de prognósticos funções que, antes, eram designadas aos seres humanos. Desse modo, porém, o problema do controle de fogo antiaéreo fez os engenheiros familiares com a noção de comunicação endereçada a uma máquina, ao invés de uma pessoa."4

Se o problema de "fogo antiaéreo" é um problema de "comunicações direcionadas a objetivos", para a incipiente ciência da cibernética sua solução está na noção do feedback regulado. $\mathrm{Na}$ cibernética, o princípio do feedback é (esteticamente) imaginado como a força operativa que guia um "mundo contingente" de seres em comunicação energética recíproca. Para Wiener, isso ocorre tanto em animais quanto nos novos computadores de alta velocidade, que a sua matemática ajudou a criar. Cada um faz uso de "órgãos sensoriais" e de dispositivos de "memória" magnética. Juntos eles operam para produzir comparações contínuas entre trocas de informação e de energia passadas e presentes. Em humanos e em outros animais, isso envolve aquilo que Wiener descreveu como "senso cinestésico", que guarda um "registro das posições e tensões em seus músculos". ${ }^{5}$ Nos novos computadores, essa função era controlada por uma combinação de rastreamento de informações e de mecanismos de gravação. Mas além da "comparação de estímulos voltados para objetivos" registrada e contínua, os processos de feedback cibernéticos envolvem algo mais interativo - "um fluxo recíproco" de "interação em duas vias entre o controlador e o controlado". Isso opera "não apenas para comunicar influência do controlador para o controlado, mas também para comunicar de volta os resultados dessa ação". ${ }^{6}$

Essa imagem de um feedback interativo me espanta como algo ao mesmo tempo perverso e utópico. Por um lado, ela celebra o controle de alguns sujeitos sobre outros. Por outro, ela descentra as práticas comunicativas que esses sujeitos utilizam para exercer controle em uma dinâmica rede de feedback interativo, formada, em parte, pelas ações comunicativas daqueles que são controlados. Em outras palavras, a cibernética substitui um modelo simplista de comando em uma só via por uma visão do processo de mandar e receber mensagens como algo mediado pela influência da própria prática comunicativa: essa seria uma influência das letras, dos ícones e das imagens em movimento. Não fique surpreso se aqui você achar semelhanças entre a cibernética, com o seu imaginário de comunicadores descentrados, amarrados a um fluxo de redes de feedback escriturais, 
textuais e providos de textura, e a imagem da vida social oferecida por certas versões da teoria pós-estruturalista. A cibernética e o pensamento pós-estruturalista emergiram em tempos e espaços historicamente relacionados (da metade para o final do século XX). Os dois estão genealogicamente relacionados, tanto no campo material quanto no imaginário. Quando estudados criticamente, cada um também sugere (potencialmente) imagens nas quais se reflete e se repete uma sensibilidade ao poder. $^{7}$

As possibilidades de comando, de controle e de comunicação da cibernética estão enraizadas no sacrifício repetido de outras maneiras de ser no e de comunicar sobre os mundos em que "nós" estamos [vivendo]. Isso faz da cibernética uma prática econômica restritiva. ${ }^{8}$ Ela sacrifica outros mundos possíveis, com o objetivo de, provisoriamente, fixar, estabilizar e controlar comunicativamente os limites que demarcam o "mundo contingente" do qual a cibernética é, em si mesma, uma parte constitutiva. A cibernética também procura monitorar, regular e modificar os circuitos dinâmicos de feedback que governam a continuidade, mas também a mudança desse mundo contingente. Na cibernética, o efeito material desses fluxos dinâmicos de feedback é a contínua modelação informacional de alguns mundos, até o ponto da redução estatística de outros [possíveis].

Nesse sentido, existe também mais que um pouco de existencialismo guiando o imaginário cibernético de Wiener. Afinal de contas, Wiener, como Sartre, estava escrevendo para combater o que ele discerniu como estrutura congelada e mortal do fascismo. Em contraste com a violência redutiva $e$ homogeneizadora do fascismo, Wiener imaginou a cibernética como oferecendo uma imagem dinâmica de intercâmbio comunicativo entre seres heterogêneos; energicamente rastreando, monitorando, lendo, interpretando e ajustadamente respondendo um ao outro; ao mesmo tempo em que reproduzem, modificam, defendem, resistem, concedem, penetram e/ou desfazem os limites entre eles e os outros; esses outros que, agora, aparecem ecologicamente, como se fossem meio ambiente, como se estivessem espacial e temporalmente do lado de fora [da sociedade].

Dentro e fora, a cibernética oferece um modelo de "causalidade circular". Você consegue imaginar isso? Wiener conseguiu. O que vem primeiro: a galinha cibernética ou um ovo dourado? A resposta, com certeza, é nenhum dos dois. Os dois são circularmente causados: interativamente, dinamicamente, reciprocamente. Não mecanicamente, mas através de uma troca energética conduzida pela informação. Não em um sentido, mas também não em todos os sentidos de uma só vez, porque quando isso acontece as coisas mudam as suas formas, se liqüefazem; perdem a sua distinção, sua capacidade de se distinguir, os seus contornos. Como a água dentro d'água ou amantes se abraçando que, ordenadamente, fazem girar os controles de feedback comunicativo contra este amável mas perigoso jogo do caos. Assim, os processos de feedback organizados facilitam a construção de limites seguros; ajudando a aquietar, absorver, silenciar, controlar e construir limites à prova de ruído. Tudo isso recoloca em questão as imagens modernas (vindas das culturas científica e popular) de "causa levando a efeito". Substituindo esse modelo linear do tipo causa e efeito, surge um imaginário teórico-estatístico mais complexo: um modelo computacional de modelação e remodelação "interativas" dos limites energéticos entre os agentes comunicativos - nem todos eles necessariamente humanos.

Ao colocar os objetos informacionais fora um dos outros, os comunicadores cibernéticos - incessantes e circulares alteram os ambientes com os quais eles e os outros interagem energeticamente. Considere a informação produzida por 
uma tela de radar em comunicação com um operador humano, dois dos primeiros "sujeito-objetos" a serem conectados no circuito eletrônico da imaginação cibernética. Aqui, a informação é:

"processada para calcular o ajuste dos controles da arma para melhorar a pontaria; a efetividade dos ajustes é observada e comunicada por radar, e então essa nova informação é usada de novo para reajustar a pontaria da arma, e assim por diante. Se os cálculos forem automatizados, a pessoa estará lidando com um dispositivo autodirecionado; de fato, o sistema inteiro de indução dos seres humanos pode ser visto como um procedimento autodirecionado". ${ }^{9}$

Situando a "nova ciência" da cibernética entre as antigas ciências da guerra, Wiener, simultaneamente, expressou horror às contribuições de outros matemáticos, cientistas e engenheiros para a construção e uso de armas nucleares. Wiener era muito desconfiado em relação às cumplicidades estruturais entre instituições científicas de elite e fontes de financiamento governamentais e militares. Em 1941, ele renunciou, em protesto, à Academia Nacional de Ciência.

Como conseqüência de seu completo afastamento do serviço governamental e militar, Wiener nunca mais recebeu financiamento estatal para a produção de conhecimento. De fato, ao longo de sua carreira posterior, Wiener operou um pouco duplamente - como cientista e como comentador da ética da prática científica. Entretanto, os sucessos das tecnologias cibernéticas nos tempos de guerra inspiraram Wiener e outros a procurar uma interface "em constante crescimento" entre comando, controle e processos de comunicação em uma diversa gama de sistemas sociais, biológicos e maquinísticos. ${ }^{10} \mathrm{Em}$ busca dessa interface, entre os anos de 1946 e 1953, Wiener reuniu-se regularmente com John von Neumann (cujos trabalhos matemáticos, diferentes dos de Wiener, contribuíram diretamente para as computações digitais necessárias aos experimentos militares norte-americanos com armamento atômico contra o Japão) e com outros ciberneticistas, em uma série de conferências muito vivas sobre cibernética patrocinada pela Fundação Josiah Macy Jr.. Também assistiram a algumas dessas sessões importantes figuras da ciência social do pós-guerra - Margaret Mead, Talcott Parsons, Gregory Bateson, Kurt Lewin e Robert K. Merton, entre outros. De forma geral, as conferências de Macy buscaram "gerar um novo tipo de ligação entre engenharia, biologia e matemática, de um lado, e entre psicologia, psiquiatria e todas as ciências sociais, de outro". ${ }^{11}$ $E$, nisso, esses pesquisadores tiveram sucesso. Se não exatamente na piscadela de um olho ou de um Eu (eye/l), então exponencialmente e firmemente, durante 0 último meio século.

$\mathrm{Na}$ condição de jovem menino branco americano nos anos cinqüenta, a cibernética me envolveu como uma segunda pele, uma segunda natureza. De fato, noite após noite, eu me deixava envolver por estados entre o sono e a vigília, recheados de feedback telecomunicativo. O rádio me embalava, me fazia rolar em algum lugar entre a vigília e a soneca eletrônica. "Telefone agora!" "Vote em suas estrelas favoritas!" Peça suas melodias negras favoritas, cantadas por vozes brancas! E, claro, eu o fiz. Nada foi igual desde então. Mas isso não é nenhuma confissão: essa é uma descrição das sinalizações cibernéticas coletivas que atravessam meu corpo, como sangue, ainda que de modo muito mais rápido. Essa é também uma descrição de um aspecto mais material da história social recente. De fato, as incorporações práticas da visão de mundo cibernética se espalharam virtualmente para todos os campos do poder, conhecimento e 
cultura. Como tais, os limites se tornaram imprecisos entre "áreas do conhecimento que foram separadas artificialmente", uma vez que "mais e mais o mundo é visto em termos de informação. Olhe para os livros de prestação de contas, as projeções, os números e os ingressos... Estoques e mercadorias, os mercados de seguros, bancos, moeda, opções, futuros... Todos esses mercados devem agora ser repensados e reestruturados", porque hoje cada um é vivido como um tipo menor, mas, ainda assim, como um tipo de troca "telemática" de feedback entre informação e energia. ${ }^{12}$

Da imaginação médica sobre seus pacientes à imaginação da CIA e da IBM sobre seus competidores e clientes e, talvez, até mesmo, de sua imaginação sobre mim mesmo, vastos "fluxos" do mundo tal como "nós" viemos a conhecêlo durante os últimos cinqüenta anos estão sendo (ritualmente) codificados e recodificados sob a forma, aparente, de simples informações.

“Até mesmo as mais simples
conversas são separadas,
reconfiguradas, enviadas e cotadas. E
aqueles que vivem neste novo mundo
estão perdendo seu controle sobre
as formas mais antigas de realidade
[assim como das outras formas
possíveis de construí-la atualmente].
Como aqueles que não têm nenhum
acesso, nem participação neste
mundo recentemente imposto, eles
são excluídos da nova economia
mundial da informação, seres
condenados à caducidade e morte."13

Em algum lugar entre a realidade e um imaginário militarizado

Retornemos ao delírio de Wiener. Em 1950, o matemático declarou que:

"é propósito da cibernética desenvolver a linguagem e as técnicas que nos permitirão realmente atacar os problemas de controle e comunicações em geral". ${ }^{14}$

Apesar da sua atitude crítica em relação às apropriações militares do conhecimento científico, é importante notar as ressonâncias militaristas de suas declarações: trata-se de ... atacar os problemas do controle e das comunicações. Tais ressonâncias permanecem profundamente entranhadas dentro da cibernética social contemporânea. Adaptese ou você está fuzilado! Além disso, dada a onipresença dos mecanismos de controle cibernéticos através de um grande número de instituições contemporâneas, é vital lembrar as origens rituais dessa lógica e de seus limites.

Certamente Wiener não estava só ao fornecer influências militares para essa nova ciência. Isso fica claro no trabalho de Donna Haraway. Haraway chama atenção para a relação entre a cibernética e a economia militarista do patriarcado capitalista, da qual ela evoluiu. Conceitualizando a lógica da cibernética como uma "ficção teórica" poderosa, que exclui outras maneiras de ver o mundo, Haraway, assim como Wiener, traça as raízes desta ideologia voltada ao trabalho de grupos interdisciplinares financiados pelo governo durante e após a Segunda Guerra Mundial. De fato, a "extraordinária organização dos cientistas durante o esforço de guerra na Inglaterra e nos Estados Unidos acabou por unir biólogos a engenheiros, lingüistas, físicos, matemáticos e administradores em uma intensa atividade que teve profundas conseqüências" no sentido de uma reorganização conceitual e prática das ciências, como, por exemplo, da biologia. A administração de sistemas socioeconômicos cotidianos também sofreu esse processo. ${ }^{15}$

Haraway nos aponta com seus trabalhos para uma cena social particular: 
uma série de locais de pesquisas efetuadas por homens brancos organizados a partir das demandas das guerras quente e fria, de o que parece ser o cenário de uma guerra perpétua. Dentro desse cenário, "os sistemas de comando e controle chamados sociedades e populações animais vieram a ser conhecidos através de procedimentos técnicos, teóricos e práticos que [não sem sacrifício] reconheceram os objetos naturais e técnicos como problemas dentro da estratégia militar; fosse na produção industrial, na qual o trabalhador é um componente do sistema cujas taxas de erro devem ser controladas através da informação e de recursos administrativos; seja no manejo psiquiátrico de sistemas comunicativos sobrecarregados ou no design criado a partir de sistemas de controle automatizados". ${ }^{16}$

"Embora tendo falhado como conceito, o éter está sendo reinventado. A informação é o derradeiro éter capaz de fazer mediação. A luz não viaja através do espaço: é a informação que viaja através da informação... a um preço alto."17

Considere, por exemplo, as idéias eletrizantes do teórico da informação Conrad Hal Waddington. Ele buscou modelar os "fluxos informacionais" em relação com os limites de energia diferencialmente limitadores. Fazendo isso, Waddington facilitou uma transferência geral de métodos associados com pesquisa operacional em organizações militares para o campo emergente da biologia molecular, onde uma nova imagem do corpo como um sistema de comunicações comandado por informações já começava a tomar forma. Nesse sentido, é crucial reconhecer que, embora por conta própria, Waddington desenvolveu suas idéias em consonância com um programa de pesquisa de tempo de guerra e que visava a reagir ao poder de fogo dos submarinos alemães, patrocinada pela British Royal
Air Force Operations Research Section. ${ }^{18}$ De resto isso não é negar o valor das descobertas de Waddington. $O$ valor é alto; mas também existem os custos. Deseja-se sugerir aqui que Waddington teorizou a vida basicamente como um problema dentro da sublime arte do jogo militar, assim como o fez Kant, durante um espaço e tempo anteriores (apesar de relacionados dentro do capitalismo), quando procurou uma linguagem capaz de justificar a alegada universalidade dos julgamentos estéticos particulares.

Nesse jogo delirante e mortal, como Waddington o desenhou, a vida corporal foi considerada como nada mais que um campo de batalha construído em torno e entre fluxos de energia e informação.

Isso também é evidente na linguagem de W. Ross Ashby, um teórico pioneiro e popularizador da cibernética. De acordo com ele:

"As características natas dos organismos vivos não passam de estratégias que se mostraram satisfatórias através dos séculos de competição e que foram construídas no animal jovem de forma a estarem prontas para o uso na primeira necessidade. Assim como muitos jogadores acharam "P-D4" uma boa maneira de abrir um jogo de xadrez, também muitas espécies acharam que "dentes crescidos" é uma boa maneira de abrir a Batalha da Vida."19

Embora isso soe um pouco como uma delirante repetição de Herbert Spencer e sua retórica sociológicoimperial da "sobrevivência daquele em melhor forma", não seria surpresa para aqueles familiares com a cibernética social proposta por um antigo sociólogo de Harvard, Talcott Parsons. Suas teorias funcionalistas dominaram o pensamento sociológico norte-americano durante os anos 50 e o início dos 60.

Além disso, sua visão da sociedade como um "sistema social" comunicativo 
representou uma síntese explícita da tese spenceriana a respeito da evolução societal adaptativa e dos desenvolvimentos recentes na ciência da cibernética. Parsons retratou os sujeitos humanos como "organismos comportamentais", cujas ações comunicativas eram guiadas por "um sistema cibernético localizado principalmente no sistema nervoso central, que opera através de diversos mecanismos intermediários para controlar os processos metabólicos do organismo e pelo uso comportamental de seus recursos físicos, tais como a movimentação dos membros". ${ }^{20}$ De fato, para Parsons, o "mesmo princípio básico da hierarquia cibernética", onde a informação comanda comunicativamente o gasto de energia, e o inverso, foi considerado "a base fundamental para classificar os componentes dos sistemas sociais". ${ }^{21}$ De importância particular foi o papel comunicativo do dinheiro como "um mecanismo cibernético no nível simbólico-cultural", capaz de "integrar ação econômica instrumental dentro do todo da sociedade como um sistema". ${ }^{22}$

Parsons usou o termo "hierarquia cibernética de controle" para descrever o ajuste ordenado dos sistemas sociais racionalmente desenvolvidos. Nesse sentido, o funcionalismo cibernético de Parsons combina o ponto de vista evolucionista de Spencer com idéias a respeito de feedback ajustável, retiradas da biologia de meados do século 20. Nas próprias palavras de Parsons, suas idéias acerca da evolução dos sistemas sociais acabados "coincidiram com um conjunto de desenvolvimentos dentro da teoria biológica e na ciência em geral - notavelmente a 'nova genética' e a teoria cibernética - que indicou uma continuidade muito maior entre a evolução sociocultural humana e aquela do mundo orgânico do que havia sido (previamente e tão) amplamente avaliada". ${ }^{23}$ Parsons visualizou um intercâmbio comunicativo entre informação e energia como o cerne de um mecanismo de navegação fundamentado em um desenvolvimento social evolucionista:

"Uma fonte de mudança social pode ser os excessos tanto de informação quanto de energia na troca entre sistemas de ação. Por sua vez, esses excessos alteram as saídas informacionais ou energéticas através e dentro de qualquer sistema. Por exemplo, excessos de motivação (energia) teriam conseqüências no acionamento de papéis ou nas estruturas normativas e, eventualmente, nas orientações culturais de valor. Outra fonte de mudança vem de um suprimento insuficiente tanto de energia quanto de informação, que mais uma vez causam reajustes internos e externos na estrutura dos sistemas de ação". ${ }^{24}$

Destarte, por exemplo, conflito informacional causaria conflito normativo ou anomia, os quais, por sua vez, teriam conseqüências para a personalidade e sistemas orgânicos. Inerentes à hierarquia cibernética de controle de Parsons são os conceitos que apontam para as interconexões sistêmicas entre êxtase e mudança. Se a descrição aparentemente "neutra" de Parsons a respeito da mudança social, como um mecanismo genético de ajuste comunicativo codificado, aparece negligente às exigências sacrificiais das lutas históricas do homem pela formação do poder, talvez isso assim seja porque Parsons define tautologicamente poder como nada mais que a "capacidade de um sistema social de mobilizar recursos para alcançar objetivos coletivos". ${ }^{25}$ Isso ignora os efeitos das hierarquias sociais historicamente enraizadas e as lutas do povo oprimido contra um poder desequilibrado. Tais questões ásperas são suavizadas pelas fluidas metáforas maquinísticas da teoria cibernética.

Mas como Arthur Kroker observa, essa mudança para um conceito cibernético de poder assinala uma "grande 
virada" nas compreensões sociológicas da relação entre "cultura e economia" e entre "tipos de poder e capital". ${ }^{26}$ Mesmo quando formulada nos mais rudes termos darwinistas por Spencer, essa concepção já continha "a descoberta essencial burguesa de que a política econômica aconteceria agora dentro de uma ordem 'regulatória' de dominações e poderes". ${ }^{27}$ Um aspecto central da contribuição massiva de Parsons ao caráter disciplinar da sociologia norteamericana foi a "normalização" de tal lógica autopreservadora do sistema. Isto representa uma "descida a uma realidade virtual" institucionalmente guiada, onde "todas as referências, desde dinheiro e poder até saúde e inteligência", se tornam codificadas como se fossem "processos cibernéticos puros". ${ }^{28}$

Refletindo sobre seu próprio interesse na cibernética, Parsons nota a influência de teóricos da biologia orientados sistemicamente, como Claude Bernard e W.C. Cannon. Mas as impressões feitas pelo bioquímico de Harvard L.J. Henderson tiveram significado particular. Durante a Depressão, os influentes seminários de Henderson a respeito do sociólogo e economista italiano Vilfredo Pareto enfatizaram o papel de sistemas vivos na organização de todas as formas sociais e deles se ocupou quase que religiosamente uma ampla variedade de pensadores, incluindo Parsons, o sociobiólogo $\mathrm{E}$. O. Wilson e cientistas sociais de vários gêneros, tais como George Homans, Robert K. Merton, Henry Murray, e Clyde Kluckholm.

Henderson enfatizou a importância do modelo de Pareto de um sistema social e a noção de equilíbrio em seu ensinamento, apesar de também ser verdade que o apoio que o fisiologista de Harvard deu às idéias do intelectual italiano estava ligado ao seu elitismo antimarxista. Henderson era um conservador extremo em suas visões políticas e viu a teoria de Pareto como muitos outros que partilhavam suas opiniões viam - como uma teoria social e econômica que poderia se contrapor ao marxismo ao tentar dar conta da depressão. ${ }^{29}$

Para Henderson, como para Parsons e muitos outros que logo desenvolveriam entusiasmo pela cibernética, as teorias de Pareto proclamavam "o início de uma nova era na história do pensamento". ${ }^{30}$ Eles também pressentiram uma dissolução das fronteiras informacionais entre a sociologia, a biologia e a economia.

"Que a América da Depressão tenha se provado receptiva ao pensamento de Pareto não é surpreendente... Seu trabalho apelou a duas das maiores tendências no clima das opiniões dos anos 30: a crença na autoridade salvadora da ciência e a descrença na autoridade da tradição [O tempo se comprime no espaço, e não o contrário]. Seu positivismo foi chamativo em um clima intelectual no qual somente os clamores da ciência ainda se mantiveram inquestionáveis, e sua postura reveladora foi análoga à dos intelectuais cujas estruturas tinham sido severamente abaladas desde a quebra do mercado de ações em 1929. [Como um teórico de sistemas homeostáticos] Pareto foi largamente lido como uma espécie de resposta burguesa a Marx."31

Parsons também reconheceu o impacto da extensa "Conferência sobre a Teoria dos Sistemas", ocorrida em Chicago entre 1952 e 1957, e particularmente o papel do entomologista Alfred Emerson, que "falou... de tal maneira forte que me predispôs, e penso que a outros, em favor das então recém emergentes concepções do controle cibernético". ${ }^{32}$ Parsons era também um pensador kantiano, que compartilhava o dilema dos filósofos idealistas a respeito das dificuldades de reivindicar o conhecimento universal a partir de um ponto de vista estritamente fenomênico. Embora Kant tenha 
solucionado esse dilema se preocupando com o "gênio" desincorporado na estética do sublime, a solução cibernética de Parsons a ela se relacionava. Como o pensamento kantiano, a metafísica cristã e os jogos de guerra ultramodernos, a cibernética também é "guiada por uma compulsão subjacente à estética". ${ }^{33}$ Nisso, "a nova biologia genética dos combinantes e recombinantes contribui (analogicamente, é verdade, mas no sentido específico da similitude estrutural) para uma interpretação do poder como um 'campo de batalha' entre a herança genética ( $O$ imperativo categórico?) e para a 'escala de suas variações' empíricas (o mundo dos fenômenos?). Aqui o corpo parece desaparecer por trás de uma tela codificada por símbolos". ${ }^{34}$

Durante uma Guerra que nem foi tão Fria como se pensa ${ }^{35}$, enfim, a palavra (de certos homens) passa a ocupar lugar como algo mais originário e duradouro do que a carne. No princípio era o verbo, e o verbo foi feito carne, afirmavam os Evangelhos segundo São João. Reduzindo as energias corporais àquelas vocacionadas pela informação, a cibernética faz a mesma suposição, seguindo nisso o exemplo do capital ultramoderno.

Sacrifício digitalizado, fluxos delirantes: gatinhos, mísseis e eu

O que (ou quem) é deixado fora da imagem do mundo em que estamos quando a palavra por si só é retratada como nada mais do que "processos cibernéticos puros"? E o que assombra estas que são as mais poderosas ficções teóricas do fim do Século XX? A resposta, de acordo com Norbert Wiener, é a malignidade do caos - o ruído das formas desorganizadas e a erosão entrópica das barreiras funcionais entre sujeito e objeto" no fluxo comunicativo. Para entender isso melhor, tanto quanto as tendências dominantes dentro dos mecanismos de controle cibernético, voltemos às afirmações do próprio Wiener de seu delírio teóricocorporal.

Wiener nos informa que sua ansiedade foi deflagrada por uma inaptidão (provocada por um ataque de broncopneumonia) para fazer distinções claras entre símbolos e os objetos que eles representam - uma inaptidão para distinguir entre palavras e coisas. "Era impossível", ele sugere, "distinguir entre minha dor e minha dificuldade em respirar, o balançar das cortinas da janela e alguns pontos ainda não resolvidos no problema potencial no qual eu estava trabalhando". Mais perturbadora foi a inaptidão do ciberneticista para dizer se esta dor se revelou como uma "tensão matemática" ou se esta tensão matemática estava de alguma maneira simbolizada na dor que ele estava sentindo. Sem poder discernir claramente uma resposta significativa sobre tais assuntos, porque "os dois eram unidos de maneira muito próxima para fazer tal separação possível", Wiener se preocupa com o caráter aleatório que subverte sua busca pelo conhecimento. De fato, parece "que quase qualquer experiência pode agir como símbolo temporário para uma situação matemática que ainda não foi organizada e esclarecida". Ao refletir sobre esse momento delirante, Wiener capta "um dos motivos principais" que o direciona para a cibernética - a necessidade de reduzir um "conflito não-resolvido" a "termos reconhecíveis e semipermanentes".

Steve Heims, o biógrafo de Wiener, concorda com isso, observando no centro das paixões pessoais e teóricas do cibermatemático uma obsessão em "encontrar a possibilidade de prever através do caos ou sintetizar através do ruído" ${ }^{36}$ Mas isso foi uma difícil tarefa para Wiener, que estava convencido pela visão teórica da Física Quântica, que sugeria ver contínuas transformações entre até a aparentemente mais sólida das matérias e as ondas dinâmicas de energia que as partículas em estado sólido só se coagulam 
e congelam de forma temporária.

Wiener procurou, através dos cálculos estatísticos de Gibbsian (nãolineares), computações estatísticas, para prover uma base matemática flexível para a mecânica quântica. $E$, através do imaginário comunicativo da cibernética, fornecer um meio dinâmico de mapear as interações transformadoras que ligam e desligam energia dentro de limites apenas relativamente previsíveis.

Nisso, Wiener imaginou a si mesmo avançando além das teorias da relatividade de Einstein. Pelo ponto de vista cibernético, as idéias de Einstein, assim como as de Newton, permaneciam sobrecarregadas com uma dinâmica "absolutamente rígida sem introduzir a idéia de probabilidade. O trabalho de Gibbs, por outro lado, é probabilístico desde o começo, ainda que ambas as direções representem uma mudança no ponto de vista da física na qual o mundo como ele se apresenta é de uma ou outra forma substituído pelo mundo tal como ele é observado". 37

$\mathrm{Na}$ verdade, Wiener procurou reformular a posição de Einstein, sugerindo que em sua teoria da relatividade é impossível introduzir o observador sem também introduzir a idéia da mensagem. ${ }^{38}$ Apesar de ser claramente vantajosa em relação à "subordinação newtoniana de tudo à matéria mecânica [fixa]", a confiança de Einstein em medições mediadas por observadores de radiações óticas (unidirecionais) (do emissor ao receptor) limitou a radicalidade de suas descobertas teóricas.

Wiener argumentou que a física de Einstein esteve muito próxima das noções pré-newtonianas de Leibnitz de um universo de organismos monocelulares em comunicação ótica (deformadas no tempo e no espaço) uns com os outros. Isso vai na mesma direção das fascinações visuais-teóricas do próprio Leibnitz com os autômatos mecânicos do tipo relógio. Para Leibnitz, a concordância temporal dessas pequenas máquinas dançantes colocadas em movimento no mesmo ponto no tempo sugeriu uma harmonia preestabelecida de organismos mônadas fazendo sinais uns para os outros. Aqui, como a imagem einsteiniana da luz viajando da fonte ao receptor, "as pequenas figuras que dançam no topo da caixa musical se movem de acordo com um padrão, mas é um padrão que é fixado antecipadamente". ${ }^{39}$ Wiener sugeriu algo mais "indeterminado" e energeticamente interativo com sua visão cibernética da física. Enquanto as ondas luminosas de Einstein e as figuras dançantes de Leibnitz não mostram nenhum traço de comunicação com o mundo externo, exceto "comunicação unidirecional" guiada por um "mecanismo preestabelecido", o movimento de coisas no mundo em que Wiener se comunicava pareceu mais complexo - tanto computacio nalmente quanto ontologicamente.

Este mundo complexo Wiener compartilhou com animais "moderadamente inteligentes", tais como encantadores gatinhos: miau, miau!

"Eu chamo o gatinho e ele levanta os olhos. Eu enviei uma mensagem que ele recebeu por seus órgãos sensoriais, e ele a registra em ação. O gatinho está faminto e geme cheio de sofrimento [Sofrimento novamente. Hum. Sim, sofrimento parece uma característica repetida do delírio cibernético de Wiener. Mas sofrimento de quem?] ... O gatinho bate em um novelo...Desta vez é o emissor da mensagem.., $\mathrm{O}$ novelo gira para a esquerda e o gatinho o pega com a pata esquerda. Desta vez mensagens de uma natureza muito complicada são enviadas e recebidas pelo sistema nervoso dos gatinhos através de terminações nervosas em suas juntas, músculos e tendões, e através de mensagens nervosas enviadas pelos órgãos o animal percebe a real posição e tensões de seus tecidos. É apenas através destes órgãos que 
qualquer coisa como uma habilidade manual é possível."40

Mas acompanhar Wiener e seu cibergatinho faminto é outra espécie de comunicação complexa - uma nova geração de autômato flexível, a configuração (matemática) que sublinhou a inadequação dos rigores ótico-mecânicos prolongados de Einstein e Leibnitz. Ao contrário dos antigos autômatos, que operavam de acordo com um mecanismo pré-programado de tipo relógio, estas novas máquinas cibernéticas - e acreditem que há mais a cada momento - são caracterizadas como autômatos dirigidos por feedback, que possuem orgânicas sensoriais assim como capacidades de registrar memórias e de comparar traduções.

Isso as torna "interativamente" flexíveis em suas capacidades de comando, controle e comunicação. Em 1950, Wiener incluiu entre elas o míssil controlado, o detonador de proximidade, o abridor automático de portas, o aparato de controle para fábricas de produtos químicos, o resto do moderno arsenal de máquinas automáticas que possuem funções militares e industriais. "Eu menciono isso de forma quase inocente sobre as máquinas através das quais eu mesmo estou enviando mensagens para vocês. Tanto as reais como as imaginárias."

$\mathrm{Na}$ história cibernética de Wiener todas estas máquinas têm um inimigo comum - entropia, desorganização caótica e ruído -, o vilão da "Segunda Lei da Termodinâmica". Contra este inimigo, Wiener coloca a efetividade informacional do feedback comunicativo ordenador. Isso facilita a construção de um sistema "fechado" temporário, um enclave local contra o caos, "cuja direção parece oposta daquela do universo maior e no qual há uma tendência limitada e temporária para o crescimento da organização". ${ }^{41}$ Mas com o passar do tempo em que a "entropia aumenta ... todos os sistemas fechados no universo tendem naturalmente a se deteriorar e perder suas distinções à medida que eles se movem desde (o que a estatística de Gibbsian percebe como) do menos para o estado mais provável organizacional e de uma diferenciação na qual as formas e distinções existem, para um estado de caos e mesmice". ${ }^{42}$

Mas tendo colocado isso, Wiener então faz um salto delirante da física para uma ontoteologia de desafiando a morte, conectando a vocação contraentrópica da cibernética para os escritos de Santo Agostinho. Isso, talvez, é o mais problemático aspecto do trabalho de Wiener. Pela ligação da missão de sua nova ciência com a visão moral de Santo Agostinho, os escritos de Wiener sugerem uma perigosa tentação dentro da cibernética de subordinar assuntos corporais finitos e relativos para 0 simbolismo abstrato e infinitamente mais exigente da alma. ${ }^{43}$ Alma de quem?

Neste aspecto filosófico do trabalho de Wiener, a cibernética se torna uma ciência moral adequada para combater seu diabólico arquiinimigo: a desorganização. Wiener afirma que este inimigo não é o diabo maniqueísta com seus truques habilidosos de dissimulação, mas "o diabo agostiniano, que não é um poder em si mesmo, mas a medida de nossa própria fraqueza". ${ }^{44}$ Mas "o diabo agostiniano é estúpido": embora ele "jogue uma partida difícil", de "resistência passiva", para codificar de maneira comunicativamente ordenada, "embebendo" as mensagens informacionais em "ruído" de energia liberada, é também um diabo completamente derrotado por uma "inteligência cibernética tão rigorosa e cuidadosa quanto o seria por um borrifar de água benta". ${ }^{45}$

Neste ponto, é importante lembrar, mesmo que Wiener não faça menção a isso, que um dos mais cativantes aspectos da teologia de Agostinho é sua feroz e veemente expressão de ódio às mulheres e aos pagãos. Mas Wiener menciona apenas o ódio agostiniano ao 
caos, que ele transcodifica como sendo uma procura preservadora da vida, dos fluxos de feedback comunicativos claramente delimitados. Nos escritos de Agostinho, o caos é configurado em formas femininas diabólicas, sedutoras e pagãs. As mulheres pagãs são enfocadas como o caos, como o mal, como as "portas que levam ao demônio". ${ }^{46}$ Essa é uma figura a ser combatida fechando-se os olhos terrenos da carne masculina, enquanto se permanece interiormente com o olho aberto para o jogo infinito de espelhos que representa a perfeita identidade trinitária ("três em Um"). Isto é, simultaneamente o mesmo e o diferente.

Um apagamento totalmente informado comunicativamente da diferença - isso também é uma fantasia de autoperpetuação atemporal. Trata-se de pura autopoiese, pura simultaneidade, pura informação.

É infinitamente mais fácil imaginar, como é o caso tanto de Santo Agostinho como de Wiener, quando nenhuma mãe está envolvida. Ou, quando a única mãe envolvida é a sem carne, sagrada e fantasmagórica infomãe. "Mãe Bell" ou seja quem for. Sem ruído, sem pecado. Wiener delirantemente imagina a cibernética como uma arma sagrada e científica que estuda os circuitos de feedback comunicativo para descobrir e "exorcizar" o ruído entrópico. Nisso, ele converte os pequenos (contra-entrópicos) demônios da ciência do século 19 de Clark Maxwell em anjos informacionais. Como porteiros regulando o fluxo útil de energias etéreas, os demônios de Maxwell parecem "superar a tendência ao aumento da entropia" dentro de locais comunicativos definidos. Mas ritualmente escavando nos cofres protegidos da organização, esses demônios simultaneamente puseram o universo mais amplo em desequilíbrio. Isso é assim porque nem os humanos nem outros comunicadores jamais existem verdadeiramente em sistemas isolados. Nós nos alimentamos via exterior, o que gera energia, e nós somos, como resultado, parte de um mundo maior que contém essas fontes de nossa vitalidade. ${ }^{47}$

O mesmo vale para os anjos cibernéticos de Wiener, olhando nas portas teletrônicas do feedback comunicativo, assegurando os limites de alguns mundos contra outros, digitalmente transcodificando energia em informação. Mas a que custo? A custo de quem? Essas eram as questões que Wiener continuamente colocava para si mesmo e outros ciberneticistas. E com boa razão. Afinal de contas, o próprio trabalho de Wiener foi situado dentro de um "enclave local" muito específico: a rede científicoindustrial e militar da América capitalista na época da Guerra Fria. Este enclave estava lutando, e em grande medida com informação, não apenas contra a entropia em geral, mas contra resistências históricas e materiais à exploração sistemática das energias de outros, assim como contra as tendências à queda da taxa de lucro espoliadora.

A vigilância ética wieneriana sobre tais assuntos inicialmente inspirou alunos críticos e reflexivos, como Gregory Bateson, Anthony Wilden, Heinz von Forrester e Stafford Beers, para fazer uso das técnicas e do imaginário cibernético na luta para uma ordem de coisas mais justa e ecologicamente sadia. O imaginário cyborg ou da cibernética sensível ao poder também se configura politicamente nos escritos de numerosos escritores contemporâneos. Mas eu sinto, para o pior mais do que para o melhor, que o delírio cibernético de Wiener, assim como a busca agostiniana pelos "sistemas fechados", é atualmente mais materialmente incorporado para controle e lucro espoliador, dentro das instituições culturais e militares dominantes do capitalismo corporativo mundializado. ${ }^{48}$ Mas isso é menos para repudiar a cibernética do que para assegurar um engajamento socioeconômico, refletido, coletivo e historicamente informado com os de algum modo "hipnagógicos", quase oníricos circuitos de feedback televisivo que hoje em dia interagem tão 
inteiramente em tantos momentos da nossa vida cotidiana. Como é, então, que se faz para efetivamente retornar às cenas cibersociais de sacrifício e, assim, melhor notar, comunicar e simultaneamente expelir o fluxo injusto e doentio das energias que essas formas informacionais ligam tanto quanto as que elas exilam, esgotam ou assassinam? As respostas para essa questão não são nem simples nem singulares: também dependem do feedback que nós damos e recebemos uns dos outros.

Tendo dito tudo isso, deixo vocês com mais um pouco de feedback de Norbert Wiener, desejando a todos bons sonhos de cyborg. Na discussão de suas próprias tentativas descompromissadas de extrair sentido teórico imaginativo do "aspecto simultâneo" de um problema, Wiener direciona sua atenção para certos momentos em que os aspectos-chave da solução começam a se cristalizar.

"Muito freqüentemente esses momentos parecem aumentar ao andarem, mas provavelmente isso realmente significa que em algum momento durante a noite eu passei pelo processo de esclarecimento (deconfusion) que é necessário para estabelecer minhas idéias. Eu estou bastante seguro que pelo menos parte deste processo pode ter lugar durante o que seria geralmente descrito como sendo o sono sob a forma de um sonho. Provavelmente é mais comum para esse processo fazer parte do chamado estado hipnótico, em que se está esperando adormecer e que se encontra associado intimamente com aquelas imagens hipnagógicas que têm alguma solidez sensorial alucinatória, mas que, ao contrário das alucinações, podem ser manipuladas mais ou menos à vontade... As idéias principais não estão ainda suficientemente diferenciadas para se recorrer a simbolismos fáceis e naturais, elas suprem uma espécie de simbolismo improvisado que pode ser carregado através de vários estágios até que um simbolismo comum se torne mais possível e apropriado... O que falta a ser feito é, na maioria das vezes, pôr de lado aqueles aspectos... que ainda não são passíveis de solução."49

\section{Notas}

* Stephen Pfohl é professor do depto. de Sociologia do Boston College, Ma. - Estados Unidos e membro do comitê editorial da revista eletrônica Ctheory (Toronto, Canadá). "O Delírio cibernético de Norbert Wiener" foi publicado inicialmente nesse veículo e, de forma impressa, em Arthur \& Marilouise Kroker (orgs.): Digital delirium (Nova York: St. Martin's Press, 1997). Traduzido por Fernanda Albuquerque, Jorge Fayet, Rafael Lime e Leandro Rodrigues. Coordenação e revisão de Francisco Rüdiger.

1 Norbert Wiener, como citado em Steve Heims, John Von Neumann e Norbert Wiener; From Mathematics to the Technologies of Life and Death. Cambridge: MA MIT Press, 1980, p. 147-148.

2 KROKER, Arthur e WEINSTEIN, Michael. Data Trash: the Theory of the Virtual Class. New York: St. Martin's Press, 1994, p. 7.

3 VIRILIO, Paul. War and Cinema: the Logistics of Perception. Minneapolis: University of Minnesota Press, 1990, p. 4-6.

4 WIENER, Norbert. The Human Use of Human Beings: Cybernetics and Society. Londres: Free Association Books, 1989 (1950), p. 147-148.

5 Ibid., p. 24.

6 WIENER, Norbert. Cybernetics, or Control and Communication in the Animal and the Machine. Cambridge: MA MIT Press, 1961, $2^{\mathrm{a}}$ ed., p. 11.

7 Tomo emprestado aqui o termo "sensível ao poder", cunhado por Donna Haraway, que o utiliza para 
sugerir uma dimensão crítica das ênfases "situadas" na objetividade, da maneira que essas funcionam auto-reconhecidamente dentro (ou contra) do cerne de configurações contextuais de poder. Veja Simians. Cyborgs and Women: the Reinvention of Nature. Nova York: Routeldge, 1992, p. 196. Em outras partes, eu próprio uso o termo "reflexivo ao poder" para indicar conceitos metodológicos. Veja Images of Deviance and Social Control: a Sociological History. New York: McgrawHill, 1994.

80 meu uso do termo "econômico restritiva" convida a uma comparação entre a cibernética e a física social de Georges Bataille. Bataille, um contemporâneo de Wiener, oferece uma teoria de uma "economia geral" que, como a cibernética, situa os movimentos da vida dentro de um campo dinâmico de intercomunicações fluentes. No entanto, Bataille sublinha o caráter repressivo e limitado das comunicações econômico restritivas, aquelas que "utilmente" estabelecem fronteiras "trabalháveis" entre sujeitos e objetos. A cibernética se restringe ao estudo dessas formas comunicativas "menores" que, apesar da sua utilidade, limitam tragicamente o brilho convulsivo das comunicações maiores. Para Bataille, a poesia vertiginosa das comunicações maiores está associada com 0 reino estático de uma "comunhão" mais íntima com as abundantes energias da vida. 0 modelo de comunicação de Bataille era assim espiral: sugerindo troca periódica, não só entre seres identificáveis "aprisionados" dentro dos giros de feedback de formas comunicativas restritivas - as coisas do cotidiano -, mas também entre as próprias formas de comunicação maiores e menores - momentos festivos de efusão sagrada em que as fronteiras se dissolvem e seres dançam indiferenciadamente como em "um córrego d'água ou numa corrente elétrica". Veja G. Bataille. Sacrifice. October 36 (outubro de 1986), p. 61-74

9 Steve Heims, John von Neumann e Norbert Wiener, op. cit., p. 184.

10 Para um discurso das contribuições científicas de Wiener e de von Neumann no período da guerra, veja a obra acima citada de Steve Heims, John von Neumann and Norbert Wiener. Von Neumann, já consultor científico do Laboratório Balístico do exército americano nos anos que precederam à II Guerra Mundial, realizou contribuições matemáticas estratégicas para 0 desenvolvimento de máquinas de computação digital, possibilitando os cálculos complexos e de alta velocidade necessários para a criação e a produção da bomba atômica. Wiener, cujas preocupações com os processos de retroalimentação cibernéticos estavam aliadas a uma preocupação em relação aos usos potencialmente "desumanos" desse conhecimento, ao saber da utilização do armamento atômico pelos EUA, retirou-se inteiramente do serviço militar e governamental, tornando-se um "erudito independente" e nunca mais voltando a aceitar financiamento do governo para o seu trabalho com a cibernética.

11 HEIMS, Steve. The Cybernetics Group. Cambridge: MIT Press, 1991, p.17.

12 Yurik, Metatron, pp. 40, 74, 12.

13 Ibid., p. 3.

14 Wiener, N. The Human Uses of Human Beings, p. 17.

15 HARAWAY, Donna. "The High Cost of Information in PostWorld War II Evolutionary Biology: Ergonomics, Semiotics, and the Sociobiology of Communication Systems". In: The Philosophical Forum, Vol. XIII, Nos. 2-3, (Winter-Spring 1981-82), p. 249.

16 Haraway, "The High Cost of Information", p. 246.

17 Ibid., p. 9.

18 Ibid., p. 249.

19 W. Ross Ashby, como citado em Haraway, Ibid., p. 249.

20 Parsons, A Paradigm for the Analysis of Social Systems, $p$. 172.

21 Ibid, p. 173.

22 PARSONS, Talcott. Social Systems and the Evolution of Action Theory. New York: The Free Press, 1977, p. 267.

23 lbid., p. 238.

24 TURNER, Jonathan. The Structure of Sociological Theory. 5th ed. Belmont, CA: Wadsworth, 1991, p. 67.

25 PARSONS, Talcott. Social Theory and Modern Society. New York: The Free Press, 1967, p. 225. 
26 Arthur Kroker, "Parsons' Foucault," in Arthur Kroker and David Cook, The Postmodern Scene: Excremental Culture and Hyper-Aesthetics. New York: St. Martin's Press, 1986, pp. 215-242.

27 Ibid., p.216.

28 Arthur Kroker and Michael A. Weinstein, Data Trash, op. cit, p. 51.

29 HAMILTON, Peter. Talcott Parsons. London: Tavistock, 1983, pp. 59-60.

30 Lawrence J. Henderson, citado em Lewis A. Coser, Masters of Sociological Thought. 2a. ed. New York: Harcourt, Brace Jovanovich, 1977, p. 422.

31 Coser, Masters of Sociological Thought, p. 423.

32 Talcott Parsons, "On Building Social Systems Theory," Daedalus, (outono de 1970), p. 831.

33 Yurik, Metatron, p. 7.

34 Kroker, "Parsons' Foucault," p. 217.

35 A cumplicidade de Parsons com as demandas políticas por informação durante a Guerra Fria é talvez ela mesma sintomática da situação da cibernética dentro da metafísica dos EUA militarizado. De fato, nos anos imediatamente seguintes à II Guerra Mundial, a pedido do Serviço de Inteligência e do Departamento de Estado americano, Parsons se engajou em uma série de ações secretas que objetivavam frustrar as regras oficiais do governo, ajudando a recrutar colaboradores nazistas russos, incluindo um cientista social procurado como "criminoso de guerra", a fim de melhor coletar informações tipo Guerra Fria sobre a União Soviética. Veja, por exemplo, Jon Wiener, "Talcott Parson's Role: Bringing Nazi Sympathizers to the U.S.," The Nation, 6 de Margo de 1989, pp. 306-309.

36 Steve Heims, John von Neumann and Norbert Wiener, op. cit., pp. 146-147.

37 Norbert Wiener, The Human Use of Human Beings, p. 20.
40 lbid, p. 22.

41 lbid, p. 12.

42 Ibid.

43 Minha leitura de Santo Agostinho, aqui, é, em parte, sugerida pela leitura provocativa de Arthur Kroker e David Cook, que vêem Santo Agostinho como um precursor do símbolo de poder descorporificado que representa a "cena pós-moderna" contemporânea. De acordo com Kroker e Cook: "a cena pós-moderna, de fato, começa no século IV com a subversão agostiniana do poder personificado", já que "a recusa agostiniana" pressagia a "implosão fatalística da experiência, ao defender que a própria cultura ocidental marcha sob 0 signo do nillismo passivo e suicida". Arthur Kroker e David Cook, The Postmodern Scene: Excremental Culture and Hyper-Aesthetics, op. cit., p. 8.

44 lbid, p. 35.

45 Ibid.

46 Veja, por exemplo, discussões sobre esses assuntos em Monica Sjoo e Barbara Mor, The Great Cosmic Mother: Rediscovering the Religion of the Earth. San Francisco: Harper and Row, 1987; John A. Philips, Eve: The History of an Idea. San Francisco: Harper and Row, 1984.

47 lbid, p. 29.

48 Veja, por exemplo, Les Levidow e Kevin Robins (eds.), Cyborg Worlds: the Military Information Society. London, Free Association Books, 1989; Chris Hables Gray, Heidi J. Figueroa-Sarriera e Steven Mentor (eds), The Cyborg Handbook. New York: Routledge, 1995; e William Bogard, The Simulation of Surveillance: Hypercontrol in Telematic Societies. New York: Cambridge University Press, 1996.

49 Norbert Wiener, como citado em Steve J. Heims, John von Neumann and Norbert Wiener, op. cit., p. 150.

38 Ibid., p. 20.

39 Ibid., p. 21. 